\title{
LexCult
}

| RESENHA

\section{RESENHA DO LIVRO: SALOMON, MARLON (ORG.). SABER DOS ARQUIVOS. GOIÂNIA: EDIÇÕES RICOCHETE, 2011, 110 p. ${ }^{1}$}

\section{Marilene Antunes Sant Anna ${ }^{2}$ Marcia Teixeira Cavalcanti ${ }^{3}$}

Recebido em: 05/08/2021 Aceito em: 13/08/2021

O livro "Saber dos Arquivos", de 2011, apresenta uma coletânea de artigos organizada por Marlon Salomon. A coletânea reúne textos de historiadores e filósofos que se propuseram a pensar sobre o papel que os arquivos desempenham nas sociedades contemporâneas e sua relação com a construção de identidades. O livro é composto de cinco capítulos que discutem desde a relação do Estado com os arquivos até os novos usos sociais que destes podemos fazer, ou que já estamos fazendo, como coloca Artières, no seu texto "Monumentos de papel: a propósito de novos usos sociais dos arquivos", parte da coletânea.

Em "Resistir às razões do Estado", Sonia Combe, pesquisadora do Instituto de Ciências Sociais do Político (CNRS) da Universidade de Paris (Oeste-Nanterre), discute as reações causadas pela votação da terceira lei sobre os arquivos promulgada pela República francesa, em 15 de julho de 2008. Para ela, esta lei se inscreve na continuidade da anterior, e busca identificar, em seu artigo, três características deste dispositivo legal para promover uma discussão sobre como as leis se articulam. A primeira característica identificada aponta que a nova lei cria uma categoria potencialmente perigosa: a de arquivos confidenciais. De acordo com a autora, essa categoria é algo que não deveria ser tolerado em qualquer democracia.

\footnotetext{
${ }^{1}$ Esta resenha foi publicada, originalmente, na Revista Oficina, vinculada ao curso de graduação de História da extinta Universidade Gama Filho. O periódico teve duas edições que não estão mais acessíveis ao público.

${ }^{2}$ Doutorado em História pelo Programa de Pós-Graduação em História Social (UFRJ), Brasil (2010); Coordenação do curso de Pedagogia da Universidade do Estado do Rio de Janeiro, Brasil.

${ }^{3}$ Doutorado em Ciência da Informação pela Universidade Federal do Rio de Janeiro, Brasil (2014); Professora da Universidade Santa Úrsula, Brasil.
} 
Hoje, na França, são considerados como confidenciais documentos que permitem a fabricação de armas de destruição em massa, mas e amanhã, o que poderá ser considerado como confidencial? A autora acredita que a retenção de arquivos acaba gerando fantasmas que levam o pesquisador aos depoimentos em detrimento dos documentos, quando ambos deveriam se complementar. Além disso, a criação de segredos de Estado prejudica a própria escrita da história.

A segunda característica refere-se à persistência na nova lei da confusão entre vida privada e vida pública. A não definição clara dos contornos de quais informações se referem à vida privada levam ao aumento do tempo de permissão para se consultar os documentos relativos aos atos praticados pelos indivíduos no exercício de suas funções públicas.

E por fim, a terceira característica sinaliza que a nova lei mantém o sistema de derrogação existente, que permite 0 acesso a determinados documentos protegidos apenas aos historiadores. Para a autora, este sistema é antidemocrático porque cria uma diferenciação entre os cidadãos, além do fato de que a política de derrogação pode ser liberal um dia e tornar-se restritiva no dia seguinte. Assim, conclui que as condições de escrita da história contemporânea na França, não ficaram melhores com a criação da lei de 15 de julho de 2008, pois esta perpetua os pressupostos das precedentes.

No artigo "A danação do arquivo: ensaio sobre a história e a arte das políticas culturais", Marlon Salomon, professor da Faculdade de História e do Programa de Pós-Graduação em História da UFG, discutirá sua tese de que nos encontramos sob um novo regime, o regime das políticas culturais, em que ocorre a despolitização da cultura e no qual a arte e a história deixam de ser dispositivos de subjetivação e se tornam meios de identificação da unidade do todo da comunidade. De acordo com a perspectiva do autor, a história, ao se transformar em um conjunto de manifestações culturais, acaba por perder sua potência política. Neste cenário, como ficam os arquivos? Para ele, as políticas culturais não buscam preservá-los, seu interesse é a preservação do patrimônio físico (o passado vivo) em detrimento dos arquivos (a história morta). Por outro lado, o regime das políticas culturais anuncia o fim da história e a converte em memória, em patrimônio acumulado no tempo. O documento não se converte mais em monumento, mas sim em patrimônio. Esse regime também despolitiza a arte, criando espaços e profissionais 
para sua legitimação, que definem o que vem a ser a verdadeira arte que exprime o espírito da comunidade. E os gestores da produção artística buscam promover a inovação, mas como esperar por novidades neste campo quando a própria ideia do que vem a ser arte já está definida pelo regime em vigor? No regime das políticas culturais a arte que se faz no exterior do espírito da comunidade deve ser exorcizada, ela deve ser engolida na interioridade do comum.

Em "Um saber histórico de Estado: os arquivos soviéticos", Antonella Salomoni, professora de História na Universidade de Bolonha, discute o processo de construção dos arquivos soviéticos e a transformação pelo qual passaram após a revolução, como também a profissionalização da função de arquivista. Ela propõe e defende a tese de que os arquivos soviéticos não são uma mera acumulação indistinta e plural de documentos, mas sim um projeto, formulado em conjunto com a fundação do novo Estado (do proletariado), sobre a história da ascensão do comunismo na sociedade russa. Se no ocidente, de maneira geral, temos uma certa clareza sobre a formação e a transformação dos arquivos estatais, no caso soviético a configuração destes arquivos ocorreu de forma parcialmente diferente da adotada por outros Estados. A Rússia soviética herda da Rússia czarista todo o atraso tecnológico e administrativo juntamente com seus arquivos, além da falta de profissionais qualificados. Diante da mudança no cenário político, os arquivos deixam de ser instituições fornecedoras de "informações práticas" confidenciais aos funcionários do Estado para se transformarem em locais que reúnem "o material mais precioso do passado". O momento era de abrir esses arquivos, torná-los públicos, e para isso era necessário modernizá-los e requalificar mental e profissionalmente os funcionários herdados da burocracia czarista. Após a revolução, o esperado era que os arquivos contribuíssem para o desenvolvimento da ciência histórica, e ao herdar esses arquivos, o historiador soviético deveria assumir três atitudes essenciais: abrir os acervos e revelar seus conteúdos; encontrar nestes acervos os sinais da oposição política dos operários, dos camponeses e dos intelectuais ao absolutismo; anexar ao patrimônio recebido a documentação referente aos partidos da revolução. A questão central está na escolha sobre fundar uma nova ordem arquivística ou inscrever uma nova ordem histórica nos arquivos existentes. A autora considera muito cedo ainda para afirmarmos se a historiografia soviética atingiu o intento de situar os arquivos das memórias operárias nas bases 
RESENHA DO LIVRO: SALOMON, MARLON (ORG.).

SABER DOS ARQUIVOS. GOIÂNIA:

EDIÇÕES RICOCHETE, 2011, $110 p$.
Marilene Antunes Sant Anna

Márcia Teixeira Cavalcanti

de fundação do novo Estado, através do uso da narrativa para relatar os acontecimentos da vida operária, mesclando à documentação presente nos arquivos herdados, que passariam a exercer uma função de fonte secundária.

O artigo "Das ordens no arquivo", do professor de Filosofia da Universidade de Tel Aviv, Adi Ophir, já tem em seu título original uma provocação inicial aos leitores. Em francês o título "Des ordres dans l'archive" denota uma ambiguidade percebida fonologicamente na junção das duas primeiras palavras, de onde se obtém o mesmo som da palavra 'désordre' que significa desordem, desorganização, caos, questionamento que o autor realiza ao longo do capítulo quando discute que o arquivo não é somente um lugar institucional, mero repositório da História, mas um "domínio fenomenológico ao qual o discurso histórico se confronta sempre e que organiza e reorganiza, controla e explicita" (Ophir, 2011, p. 76). Assim, o arquivo para o autor, a partir de uma abordagem epistemológica, é o lugar onde se concretizam os discursos (históricos), levando-se em conta que esses não dizem respeito somente aos fatos do passado, da História, mas são vistos como redes de saber e poder produzidas no passado e que fazem sentido para o historiador contemporâneo. Nesse sentido, seu conceito de arquivo aproxima-se bastante das discussões presentes na "ordem do discurso" de Foucault. Para o pensador francês, o arquivo é um campo de possibilidades, "é o que faz com que todas as coisas ditas não se acumulem indefinidamente em uma massa amorfa, não se inscrevam, tampouco, em uma linearidade sem ruptura e não desapareçam ao simples acaso de acidentes externos, mas que se agrupem em figuras distintas, se componham umas com as outras segundo múltiplas relações, se mantenham ou se esfumem segundo regularidades especificas (...)" (Foucault apud Ophir, 2011, p. 87). Por arquivo, então, Foucault entende um sistema de formação e transformação que faz os discursos subsistirem e se modificarem ao longo do tempo. Por fim, para Adi Ophir deve o historiador vencer a ordem projetada, hipotética, que em geral vem sendo imposta na arrumação dos arquivos. Citando Nietzsche, que defende a existência de um abismo entre os fenômenos históricos apresentados e a realidade que eles supõem representar, o professor Ophir recomenda que o objetivo do historiador, considerado como um arqueólogo, seja reordenar o arquivo à luz das experiências e das práticas do discurso histórico contemporâneo. 
O último texto da coletânea intitulado "Monumentos de papel: a propósito de novos usos sociais dos arquivos" traz um historiador conhecido na academia brasileira: Philippe Artières, professor do Instituto Interdisciplinar de Antropologia do Contemporâneo da Escola de Altos Estudos em Ciências Sociais (CNRS/EHESS) de Paris. Neste capítulo, em particular, Artières destaca que para além dos arquivos institucionais, criados sob a chancela dos Estados, há atualmente um interesse dos indivíduos, redimensionado pelo fenômeno da internet, em torno dos arquivos privados. Para o autor, tal movimento teve início nos anos 1990 quando ocorreu uma política de descentralização dos poderes e das finanças em prol de lugares de memória e patrimônio representativos das identidades locais e também por um crescente interesse pela história, o qual "tomou a forma de um desejo de se apropriar dela através da produção de uma série de histórias de si”, (Artières, 2011, p. 101). A conjunção dessas duas direções teria levado pessoas de notoriedade diversa (principalmente anônimos) a conservarem seus escritos pessoais e o crescimento dessa situação levaria a uma "pequena revolução arquivística", no sentido de não mais os historiadores, arquivistas, antiquários, serem os únicos na contemporaneidade a cuidar do passado. Para defender seu argumento, o autor cita alguns exemplos. O mais marcante deles é o que os franceses chamam de vide-grenier, que ao pé da letra seria "esvazia sótão". Ou seja, uma venda nas calçadas, por pessoas comuns, de cartas, cartões postais, fotografias retiradas de suas casas para serem expostas e vendidas. Material esse que, segundo Artières, já foi parar nos livros, em exposições de arte contemporânea, em alguns documentários que narram o passado e também em diferentes sites da internet onde na categoria 'papéis velhos' vendem-se e compram-se on-line muitos arquivos pessoais. Na segunda parte do texto, o autor se pergunta justamente o que a internet faz hoje em dia com os arquivos. A internet divulga, populariza a história e a vida cotidiana cada vez mais. Existem sites onde o internauta põe em cena sua história familiar, constituindo-se não raras vezes em verdadeiros arquivos privados. Há ainda um outro lado que o autor destaca, que trata da própria composição desses arquivos digitais, que não acumulam poeira e não ocupam espaço. $\mathrm{Na}$ contemporaneidade essa nova ordem arquivística traz uma crítica a ordem tradicional dos arquivos e vem cada vez mais ocupando espaços institucionais, culturais em que tal discussão não pode mais ser negligenciada. 